\title{
Isolation of Multidrug Resistant Salmonella spp. from the River Yamuna in Delhi Region of India
}

\author{
Shingini Sharma ${ }^{1,2 *}$, V. Samuel $\operatorname{Raj}^{1}$, Kusum Rani ${ }^{1}$ and Rashmi Tyagi ${ }^{1}$ \\ ${ }^{1}$ Department of Microbiology \& Biotechnology, SRM University, Haryana, India \\ ${ }^{2}$ CCS National Institute of Animal Health, Baghpat, U.P., India \\ *Corresponding author
}

\begin{tabular}{|l|}
\hline Ke y w or d s \\
AMR, Salmonella, \\
MDR, Yamuna
\end{tabular}

The present study was conducted to explore the prevalence of multidrug resistant Salmonella spp. in the water of river Yamuna in Delhi region of India. The river Yamuna which is a major tributary of river Ganges flows through the three states of northern India comprising Delhi, Haryana and Uttar Pradesh. The samples of water for the isolation of Salmonella spp. were randomly collected from different locations of the river Yamuna flowing through the three states of Delhi NCR and processed as per standard guidelines of fssai, CDC and WHO for the isolation of the Salmonellae. The isolates were further subjected to molecular identification and serotyping. All the isolates obtained were positive for the invA gene that is highly conserved in Salmonella spp. and the major serovar found among the serotyped isolates was Salmonella Typhimurium. The isolates were subjected to AMR studies and all the isolates were found multidrug resistant for at least five drugs with multiple antibiotic resistance index (MARI) above 0.2 indicating their origin from high source of contamination. The result of this study revealed the presence of MDR Salmonella spp. in the water of river Yamuna in Delhi region which is a serious public health concern and emphasizes the need of containment of spread of MDR Salmonella spp. to the susceptible human and animals population that come in contact with the river water.

\section{Introduction}

The continuous rise in antimicrobial resistance (AMR) is a great threat to public health and is expected to lead to drastic increase in mortalities by the year 2050 (Coates \& $\mathrm{Hu}, 2018$ ). The involvement of different ecosystems comprising human, animals and the environment further worsen the situation by harbouring pathogenic, nonpathogenic and commensal bacteria carrying the resistance genes(González-Zorn \& Escudero, 2012). There are 2,610 Salmonella serotypes, (Achtman et al., 2012) of which the Salmonella Typhimurium is the most common serovar that cause human infection and the contamination of the environment (Wales \& Davies, 2013) Salmonellosis is the most common foodborne illness which is selflimiting disease in human but may also lead to life threatening systemic infections. The emergence of the AMR in Salmonella strains 
of human and animals is a major public health concern throughout the world (Vo, Van Duijkeren, Gaastra, \& Fluit, 2010). Surveillance of the AMR is important for providing information on the extent and trends in AMR (WHO, 2001). It is reported that human and animals excrete Salmonellae in the environment during the illness and the convalescent phase and the Salmonellae have the potential to survive in water and soil for several years under favourable environment (Todar, 2016). Salmonellosis is generally transmitted through oro-faecal route and faecal contamination of water (Todar, 2016). The infections are also associated with factors like consumption of contaminated food of animals origin and water (Dechet et al., 2006). In order to control and prevent the spread of AMR in Salmonellae it is of paramount importance to acquire the accurate information about the current status of circulating bacteria and its prevalence and resistance pattern in the ecosystem and since river water can transmit the infections caused by Salmonella spp. (Angulo et al., 1997) so, the present study is conducted to explore the prevalence of multidrug resistant (MDR) Salmonella spp. in water (Ahammad, Sreekrishnan, Hands, Knapp, \& Graham, 2014) of the river Yamuna flowing through Delhi region, in Northern India that serve the need of a large of population and may spread the infections caused by Salmonella spp. in human and animal population coming in contact with the river water. The river Yamuna flows through three major states of northern India comprising Delhi $\left(28.7041^{0} \mathrm{~N}\right.$, $\left.77.1025^{0} \mathrm{E}\right)$, Haryana $\left(28.9931^{0} \mathrm{~N}, 77.0151^{0}\right.$ E) and Uttar Pradesh $\left(29.0468^{\circ} \mathrm{N}, 77.3324^{0}\right.$ E). The water of river is polluted by several sources and harbour many multidrug resistant Salmonella, (Azam, Jan, \& Haq, 2016) which bear the potential to transfer the resistance genes, (Walsh, C., 2003) to different bacteria via horizontal gene transmission, (Lavigne \& Blanc-Potard, 2008) so the study of MDR
Salmonella and its AMR pattern becomes more important to contain its spread.

\section{Materials and Methods}

\section{Isolation}

A total of 168 samples were collected in sterile containers of $250 \mathrm{~mL}$ from 14 different locations comprising barrages, banks and bridges of river Yamuna located in Delhi, Haryana and Uttar Pradesh (India). Water samples were collected from six different locations of Delhi. Five to seven samples were from different spots of each location. $250 \mathrm{~mL}$ of water was collected in sterile containers from 1-2 meters of water from river bank. Samples were collected both from surface water and under the surface water. The samples were transported to laboratory in cold chain and maintained at $4{ }^{0} \mathrm{C}$ till further processing. Salmonella organisms were isolated from water as per the guidelines of fssai Manual of Methods of Analysis of FoodWater, 2016 (fssai, 2016). To check the stool and faecal contamination of water the samples were processed for both typhoidal and nontyphoidal Salmonella as per the methods described in Standard ISO 6579: (2002) and also in accordance with the new revised Guidelines of ISO 6579, 1:2017, (Mooijman, 2018) and CDC/WHO manual (Perilla et al., 2003). Salmonella spp. organisms were identified using the methods described by Ewing (Ewing, 1986) and McCartney ("Mackie and McCartney Practical Medical Microbiology, 14th Edition," 1996).

Pre-enrichment of the samples was done in Buffered Peptone Water (Hi-media, Mumbai, India) whereas multiple selective enrichment media were used for isolation of Salmonella spp. from water and faecal samples. In this study at least 2 selective enrichment media were used for each sample in order to ensure the recovery of Salmonellae. Enrichment 
media, (Mooijman, 2018) used were Tetrathionate broth (Hi-media, Mumbai, India) for isolation of non-typhoidal Salmonella (NTS) and Selenite F broth (Himedia, Mumbai, India) for Typhoidal Salmonella. Three selective media Hoektoen Enteric Agar (Hi-media, Mumbai, India) and Xyline deoxycholate Agar medium (Himedia, Mumbai, India) and Xylose lysine Tergitol-4 (Difco, USA) were used for isolation of Salmonella spp. Mac Conkey's Lactose Agar (Hi-media, Mumbai, India) was used as differential media, Nutrient Agar (Himedia, Mumbai) and Trypticase Soy Agar (Difco, USA), Trypticase Soy broth (Difco, USA), were used for culture revival and storage.

\section{Characterization of Salmonella spp.}

Cultural: Salmonella spp. were isolated from different sources was subjected to cultural characterization. The cultures were inoculated on different selective and differential media, (Blood \& Curtis, 1995) as per the methods described by Ewing and McCarntney (Ewing, 1986; "Mackie and McCartney Practical Medical Microbiology, 14th Edition," 1996).

Morphological: Isolates were subjected to the Gram's staining for their morphological characterization as per the methods described by Ewing and McCartney (Ewing, 1986; "Mackie and McCartney Practical Medical Microbiology, 14th Edition," 1996).

Biochemical: The test culture was streaked on the surface of the TSI agar slant (Maness et al., 1999) and also stabbed up to the butt of the agar medium. Inoculated TSI agar slant was incubated at $37{ }^{0} \mathrm{C}$ for 24 hours as per the methods described by Ewing and McCartney (Ewing, 1986; "Mackie and McCartney Practical Medical Microbiology, 14th Edition," 1996). The culture medium showing alkaline reaction (red) in the slant an acidic reaction, (yellow) in the butt and with blackening of the medium along the stab line due to hydrogen sulphide gas production in TSI agar medium was interpreted as positive test. The test culture was streaked over the surface of the slope of the Christensen's urea medium and incubated at $37{ }^{\circ} \mathrm{C}$ for 24 hours. A positive test was indicated by the development of pink colour in the medium. In case of negative test, no change of colour was found in the medium.

The culture tube showing negative test after 24 hours of incubation was further incubated for 7 days to observe colour change in the medium. Isolates showing no development of pink colour in the medium even after 7 days of incubation were considered urease negative. The test culture of organism was also subjected to citrate test with change to blue colour and presence of growth in citrate slant as positive test while negative test was indicated by absence of growth and colour change.

\section{Molecular identification}

Molecular identification of Salmonella spp. isolates was done by PCR for invA gene (Chiu \& Ou, 1996; Malorny, Hoorfar, Bunge, \& Helmuth, 2003). The invA gene is highly conserved and used for the identification of the Salmonella spp., (Malorny, Huehn, Dieckmann, Krämer, \& Helmuth, 2009). DNA was extracted by thermal lysis. The final concentration of DNA was adjusted to $50 \mathrm{ng} / \mu \mathrm{L}$. PCR reaction mixture consisted of $12.5 \mu 1$ of $2 x$ PCR master mixtures (Thermo Scientific $), 1 \mu \mathrm{L}(10 \mathrm{pmol} / \mu \mathrm{L})$ of each primer (Eurofins, India), $2 \mu \mathrm{L}$ of DNA template and nuclease-free water to make final volume up to $25 \mu \mathrm{L}$.

The cycling condition comprised an initial denaturation at $94^{\circ} \mathrm{C}$ for $5 \mathrm{~min}$, followed by 30 cycles each of denaturation at $94^{\circ} \mathrm{C}$ for 1 
min, primer annealing at $51^{\circ} \mathrm{C}$ for $1 \mathrm{~min}$, elongation at $72^{\circ} \mathrm{C}$ for $1 \mathrm{~min}$ and finally a single extension step at $72^{\circ} \mathrm{C}$ for $7 \mathrm{~min}$. The PCR products were resolved by agarose gel electrophoresis (1.5\%) stained with $0.5 \%$ ethidium bromide and documented under gel documentation system (Bio-Rad).

\section{Serotyping}

The isolates of Salmonella spp. obtained from water samples were sent for serotyping to Salmonella Typing centre, Indian Veterinary Research Institute, Izatnagar, Bareilly, India.

\section{Antimicrobial susceptibility testing}

Disk diffusion tests were performed as per Manual of antimicrobial susceptibility testing, (Huehn et al., 2010) and Clinical Laboratory and Standard Institute, (CLSI, 2016) using disks (Himedia Pvt. Ltd., Mumbai, India) impregnated with Ampicillin (AMP; 10), Amoxyclav (AMC;30), Azithromycin (AZM; 15), Aztreonam (AT; 30), Cefotaxime (CTX; 30), Cefotaxime/ Clavulanic acid (CAC;30/10), Cefoxitin (CX;30), Cefpodoxime (CPD;10), Ceftazidime
(CAZ;30),Ceftazidime/ Clavulanic acid (CEC; 30/10), Ceftriaxone

(CTR;30), Chloramphenicol

(C;30), Ciprofloxacin (CIP;10),Clindamycin (CD;2), Colistin (CL;10),Co-Trimoxazole (COT;25),Gentamicin (GEN;10), Imipenem (IPM; 10), Levofloxacin (LE;5), Meropenem (MRP;10), Nalidixic acid (NA; 30), Nitrofurantoin (NIT;300), Piperacillin/ Tazobactum (PIT;100/10), Polymyxin B (PB;300units), Streptomycin (S;10),Tetracycline (TE;30), Tigecycline (TGC;15), Tobramycin (TOB;10). European Committee on Antimicrobial Susceptibility Testing, (European Committee on Antimicrobial Susceptibility Testing, 2016) guidelines were used where CLSI guidelines were insufficient. (Arthur L. Barry, William A. Craig, Harriette Nadler,:. Barth reller, Christie C. Sanders, 2016) Escherichia coli (ATCC 25922), Salmonella enterica subsp. enterica serovar Enteritidis (ATCC13076), Salmonella enterica subsp. enterica serovar Typhimurium (ATCC 51812) were tested as controls under the same conditions as was suggested by CLSI (Arthur L. Barry, William A. Craig, Harriette Nadler,:. Barth reller, Christie C. Sanders, 2016).

\begin{tabular}{|c|c|c|c|}
\hline \multicolumn{4}{|c|}{ Oligonucleotide Primer Sequences } \\
\hline F:GTGAAATTATCGCCACGTTCGGGCAA & invA & $284 \mathrm{bp}$ & Rahn et al., 1992 (Rahn et \\
\cline { 1 - 2 } R: TCATCGCACCGTCAAAGGAACC & gene & al., 1992) \\
\hline
\end{tabular}

\section{Results and Discussion}

Isolation: A total of 11 isolates were obtained out of 168 samples (Table 1). The prevalence of Salmonella isolates obtained from the 14 different locations of water collection from the river Yamuna flowing through the three states comprising Delhi, Haryana and Uttar Pradesh was $6.55 \%$. All the isolates were obtained from Yamuna Bank region of Delhi except one isolate was obtained from ITO Bridge of Delhi.

\section{Cultural characterization}

Salmonella spp. isolates showed different cultural characteristics on different media. Colonies of Salmonella spp. appeared as moderately large, moist, smooth and colourless with pink background on brilliant green agar (BGA), blue green colour colony with black center on Hektoen enteric agar and red colony with a black center on xylose lysine deoxhycholae agar (XLD)/XLT4 Agar and colour less colonies on Mac Conkeys lactose agar. Salmonella on MLA that 
appeared transparent and pale due to no acid production whereas the $E$. coli colonies on MLA appeared pinkish as the negative control E. coli (ATCC25922) being a lactose fermenter, it fermented the lactose present in the MLA and produced the acid that lowered the $\mathrm{pH}$ of the media due to which the indicator neutral red present in the media gave pink colouration. The XLD media contained phenol red indicator that was pink in alkaline medium and yellow in acidic medium. The medium had sugar xylose that was well utilised by the Salmonella but not by Shigella and acid is produced, but on exhaustion of xylose Salmonella utilised the lysine present in the media due to which the $\mathrm{pH}$ again increased to alkaline and then Salmonellae metabolised thiosulfate to produce hydrogen sulphide due to which a black centre in the colonies of Salmonella appeared on XLD media. The agar too turned red due to the presence of Salmonella type colonies whereas negative control E. coli produced yellow colonies with characteristics bright yellow media background due to acid production due metabolism of sugars present in the media by the negative control $E$. coli. The HEA media contained various sugar source viz. lactose, sucrose, and salicin none of which were used by the Salmonella but the medium also comprised peptone which was metabolised by Salmonella to produce the alkaline environment in the media turning the Bromothymol blue ( $\mathrm{pH}$ indicator) from green to blue so Salmonella on HEA agar produced blue green colonies with black centre due to hydrogen sulphide gas with blue background of media whereas negative control E. coli produced pale yellow colonies and pinkish or yellowish background of media that was produced due to the production of acid on metabolism of various sugars present in the media by the E. coli. The XLT4 media had anionic surfactant Niaproof earlier known as Tergitol-4 and was highly selective for Salmonella, rest the mechanism of isolation was similar to that of XLD with phenol as indicator. Salmonella produced pinkish colonies with black centre on XLT4 media with the pinkish background of media whereas negative control E. coli colonies appeared pale with a bright yellow background of media due to acid production.

\section{Biochemical characterization of Salmonella spp.}

All the Salmonella spp. isolates were subjected to different biochemical tests comprising Oxidase, Catalase, Indole, MR, VP, Citrate, TSI and Urease and all the isolates exhibited Indole negative, MR positive, VP negative, Citrate positive, TSI (K/A) with $\mathrm{H}_{2} \mathrm{~S}$ production and urease negative results.

\section{Molecular characterization of Salmonella spp.}

PCR assay for invA, followed by agarose gel electrophoresis revealed specific amplification of a $284 \mathrm{bp}$ nucleotide segments indicating presence of invA gene (Fig.1).

\section{Serological characterization of Salmonella spp.}

The water of river Yamuna though showed highest prevalence of Salmonella spp. in the region of Yamuna Bank, Delhi. Selected isolates were subjected to serotyping to identify their antigenic characteristic. The results revealed that most of the samples belonged to Serovar Salmonella Typimurium with antigenic structure as 4,5,12:i:1,2, one isolate S2 belonged to Serotype Group C2 with antigen 6,8 and one of the isolate S14 was untypable. $S$. Typhi was not isolated from any location. Isolates exhibited high MARI and thus indicate that they originated from the source of high risk of contamination. 
Table.1 Details of source of Salmonella isolates

\begin{tabular}{|r|l|c|}
\hline S.No. & Isolate I.D. & Location \\
\hline $\mathbf{1 .}$ & S2 & Yamuna bank, Delhi \\
\hline $\mathbf{2 .}$ & S3 & Yamuna bank, Delhi \\
\hline $\mathbf{3 .}$ & S6 & Yamuna bank, Delhi \\
\hline $\mathbf{4 .}$ & S8 & Yamuna bank, Delhi \\
\hline $\mathbf{5 .}$ & S 9 & Yamuna bank, Delhi \\
\hline $\mathbf{6 .}$ & S11 & Yamuna bank, Delhi \\
\hline $\mathbf{7 .}$ & S12 & Yamuna bank, Delhi \\
\hline $\mathbf{8 .}$ & S13 & ITO Bridge, Delhi \\
\hline $\mathbf{9 .}$ & S14 & Yamuna bank, Delhi \\
\hline $\mathbf{1 0}$ & S15 & Yamuna bank, Delhi \\
\hline $\mathbf{1 1}$ & S16 & Yamuna bank, Delhi \\
\hline
\end{tabular}

Table.2 Salmonella spp. Resistance Pattern

\begin{tabular}{|r|c|r|c|}
\hline S.No. & Isolate No. & Resistance Pattern & Resistant Drugs \\
\hline $\mathbf{1}$ & S2 & CTX-CD-NIT-PIT-S & 5 \\
\hline $\mathbf{2}$ & S3 & AMC-AMP-CTX-CAZ-CD-NIT-S & 7 \\
\hline $\mathbf{3 )}$ & S6 & AMC-AMP-CTX-CD-GEN-NIT-S & 7 \\
\hline $\mathbf{4 )}$ & S8 & AMC-AMP-CTX-CD-GEN-NIT-S & 7 \\
\hline $\mathbf{5 )}$ & S9 & AMC-AMP-CTX-CIP-CD-GEN-NIT-S & 8 \\
\hline $\mathbf{6 )}$ & S11 & AMC-AMP-CTX-CD-GEN-NIT-S & 7 \\
\hline $\mathbf{7 )}$ & S12 & AMP-AZM-CTX-CD-GEN-NA-NIT-S & 8 \\
\hline $\mathbf{8 )}$ & S13 & AMC-AMP-CTX-CTR-CD-NA-NIT & 7 \\
\hline $\mathbf{9 )}$ & S14 & AMP-CTX-CAZ-CD-NIT-S & 6 \\
\hline $\mathbf{1 0}$ & S15 & AMC-AMP-AZM-CTX-CAZ-CD-NA-NIT-S-TGC & 10 \\
\hline $\mathbf{1 1}$ & S16 & AMP-AZM-CTX-CD-NA-NIT & 6 \\
\hline
\end{tabular}

Note:

$\mathrm{AMC}=$ Amoxicillin+Clavulanic acid, $\mathrm{AMP}=$ Ampicillin, $\mathrm{AZM}=$ Azithromycin, AT= Aztreonam, $\mathrm{CTX}=$ Cefotaxime, $\mathrm{CEC}=$ Cefotaxime/ Clavulanic acid, $\mathrm{CX}=$ Cefoxitin, $\mathrm{CPD}=$ Cefpodoxime, $\mathrm{CAZ}=\mathrm{Ceftazidime}$, $\mathrm{CAC}=$ Ceftazidime/ Clavulanic acid, $\mathrm{CTR}=$ Ceftrioxone, $\mathrm{C}=$ Chloramphenicol, $\mathrm{CIP}=\mathrm{Ciprofloxacin}, \mathrm{CD}=$ Clindamycin $\mathrm{CL}=$ Colistin, COT= Co-Trimoxazole, GEN= Gentamicin, IPM= Imipenem, LE $=$ Levofloxacin, $\mathrm{MRP}=$ Meropenam, NA= Nalidixic acid, NIT=Nitrofurantoin, PIT= Piperacillin/Tazobactum, $\mathrm{S}=$ Streptomycin, $\mathrm{TE}=$ Tetracycline, $\mathrm{TGC}=$ Tigecycline, $\mathrm{TOB}=$ Tobramycin

Table.3 Multiple Antibiotic Resistance Index of Salmonella spp.

\begin{tabular}{|c|c|c|c|c|c|}
\hline S.No. & Source & Resistance Pattern & No. of Isolate & MARI & $\begin{array}{l}\text { Average } \\
\text { MARI }\end{array}$ \\
\hline \multirow[t]{9}{*}{1.} & \multirow{9}{*}{$\begin{array}{l}\text { Yamuna } \\
\text { water }\end{array}$} & CTX-CD-NIT-PIT-S & 1 & 0.208 & \multirow{9}{*}{0.297} \\
\hline & & AMC-AMP-CTX-CAZ-CD-NIT-S & 1 & 0.292 & \\
\hline & & AMC-AMP-CTX-CD-GEN-NIT-S & 3 & 0.292 & \\
\hline & & AMC-AZM-CTX-CD-GEN-NA-NIT-S & 1 & 0.334 & \\
\hline & & AMC-AMP-CTX-CIP-CD-GEN-NIT-S & 1 & 0.334 & \\
\hline & & AMC-AMP-CTX-CTR-CD-NA-NIT & 1 & 0.292 & \\
\hline & & AMP-CTX-CAZ-CD-NIT-S & 1 & 0.25 & \\
\hline & & AMC-AMP-AZM-CTX-CAZ-CD-NA-NIT-S-TGC & 1 & 0.417 & \\
\hline & & AMP-AZM-CTX-CD-NA-NIT & 1 & 0.25 & \\
\hline
\end{tabular}


Table.4 Resistance profile of isolates of Salmonella spp.

\begin{tabular}{|r|c|c|c|c|c|c|}
\hline S.No & Antibiotic & Symbol & $\begin{array}{c}\text { Concentration } \\
(\mathbf{m c g})\end{array}$ & $\begin{array}{c}\text { Sensitive } \\
\mathbf{( \% )}\end{array}$ & $\begin{array}{c}\text { Intermediate } \\
\mathbf{( \% )}\end{array}$ & $\begin{array}{c}\text { Resistant } \\
(\mathbf{\%})\end{array}$ \\
\hline $\mathbf{1 .}$ & Amoxyclav & AMC & 30 & 9.09 & 27.27 & 63.63 \\
\hline $\mathbf{2 .}$ & Ampicillin & AMP & 10 & 0 & 0 & 100 \\
\hline $\mathbf{3 .}$ & Azithromycin & AZM & 15 & 72.72 & 0 & 27.27 \\
\hline $\mathbf{4 .}$ & Aztreonam & AT & 30 & 63.63 & 36.36 & 0 \\
\hline $\mathbf{5 .}$ & Cefotaxime & CTX & 30 & 0 & 0 & 100 \\
\hline $\mathbf{6 .}$ & Ceftazidime & CAZ & 30 & 9.09 & 63.63 & 27.27 \\
\hline $\mathbf{7 .}$ & Ceftazidime/ & CAC & 30 & 100 & 0 & 0 \\
\hline & Clavulanic acid & & & & & \\
\hline $\mathbf{8 .}$ & Ceftriaxone & CTR & 30 & 45.45 & 45.45 & 9.09 \\
\hline $\mathbf{9 .}$ & Chloramphenicol & C & 30 & 100 & 0 & 0 \\
\hline $\mathbf{1 0}$ & Ciprofloxacin & CIP & 10 & 63.63 & 27.27 & 9.09 \\
\hline $\mathbf{1 1}$ & Clindamycin & CD & 2 & 0 & 0 & 100 \\
\hline $\mathbf{1 2}$ & Colistin & CL & 10 & 100 & 0 & 0 \\
\hline $\mathbf{1 3}$ & Co-Trimoxazole & COT & 25 & 100 & 0 & 0 \\
\hline $\mathbf{1 4}$ & Gentamicin & GEN & 10 & 54.54 & 0 & 45.45 \\
\hline $\mathbf{1 5}$ & Levofloxacin & LE & 5 & 90.90 & 9.09 & 0 \\
\hline $\mathbf{1 6}$ & Meropenem & MRP & 10 & 36.36 & 63.63 & 0 \\
\hline $\mathbf{1 7}$ & Nalidixic acid & NA & 30 & 18.18 & 45.45 & 36.36 \\
\hline $\mathbf{1 8}$ & Nitrofurantoin & NIT & 300 & 0 & 0 & 100 \\
\hline $\mathbf{1 9}$ & Piperacillin/Tazoba & PIT & $100 / 10$ & 27.27 & 63.63 & 9.09 \\
\hline & ctum & & & & & \\
\hline $\mathbf{2 0}$ & Polymyxin B & PB & 300 units & 100 & 0 & 0 \\
\hline $\mathbf{2 1}$ & Streptomycin & S & 10 & 0 & 18.18 & 81.81 \\
\hline $\mathbf{2 2}$ & Tetracycline & TE & 30 & 63.63 & 36.36 & 0 \\
\hline $\mathbf{2 3}$ & Tigecycline & TGC & 15 & 72.72 & 18.18 & 9.09 \\
\hline & & & & & & \\
\hline
\end{tabular}

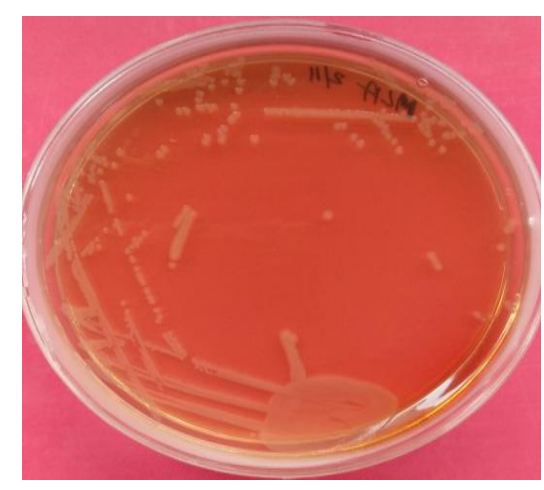

Fig.1 Salmonella on MLA media

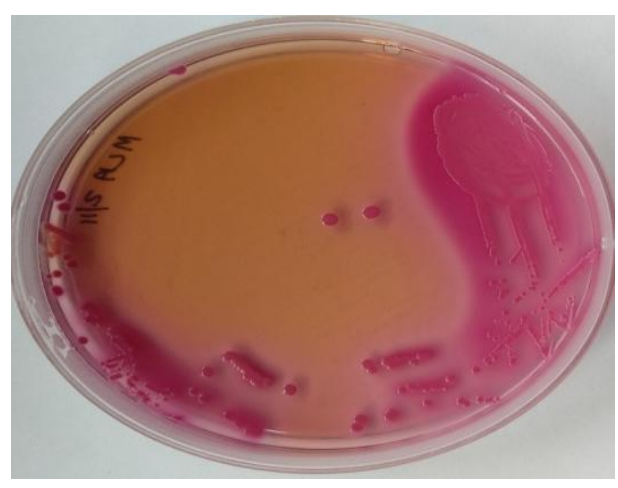

Fig.2 E. coli ATCC 25922 on MLA media 


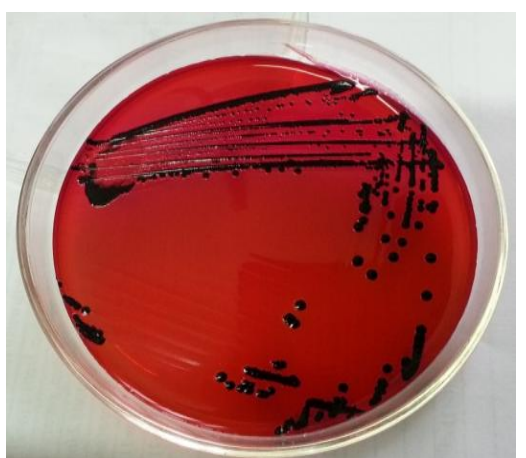

Fig.3 Salmonella Typhimurium on XLT4 plate

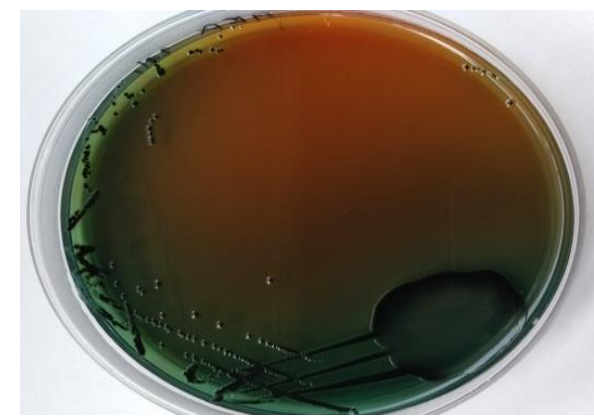

Fig.5 Salmonella on HEA media

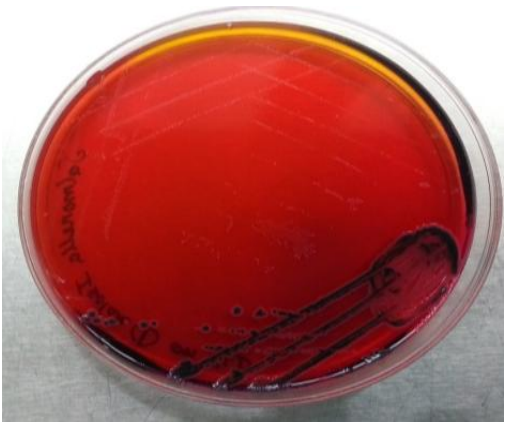

Fig.7 Salmonella on XLD media

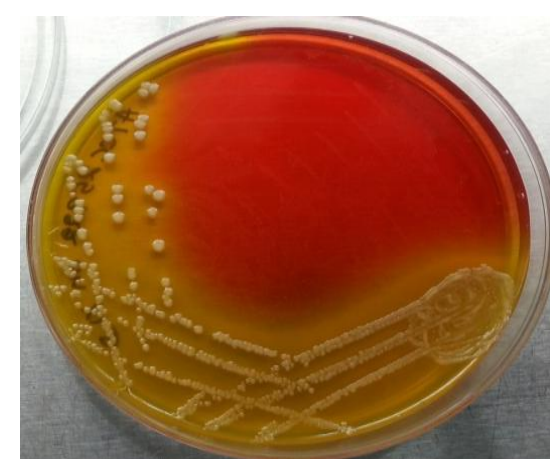

Fig.4 E.coli ATCC 25922 on XLT4 media

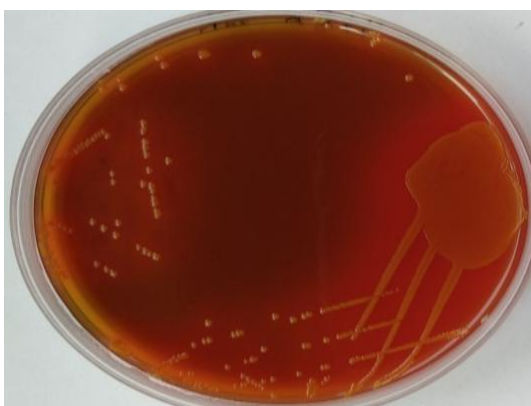

Fig.6 E. coli ATCC 25922 on HEA media

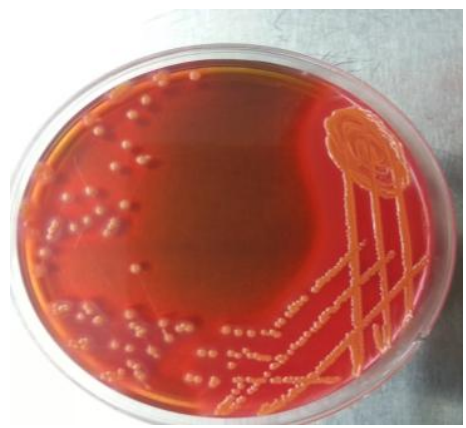

Fig.8 E.coli on XLD media

Fig.9 PCR for invA gene (284 bp) of Salmonella spp.

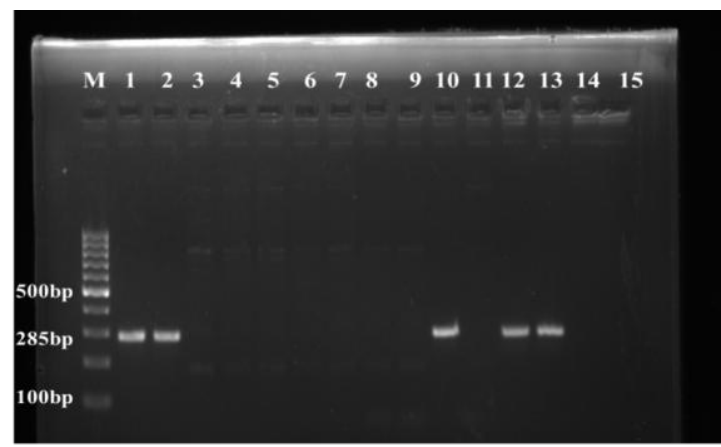

Lane 1,2,10,12,13:Positive for invA gene

Lane 3-9, 11, 14:Negative for invA gene (284bp)

Lane 15: Negative control

M: 100 bp DNA ladder 
Fig.10 Resistance profile of isolates of Salmonella spp.

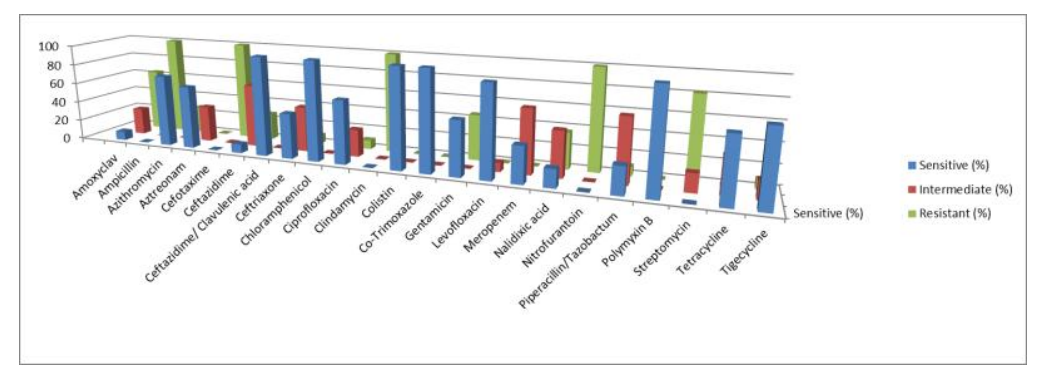

The present study was conducted to explore the existence the MDR Salmonella in the water of the river Yamuna that flows through the heart of city Delhi and surrounding regions and serve a large population of the human and animals that thrive on it and may acquire the deadly infections due the MDR Salmonella. To control and prevent the spread of AMR in Salmonella spp. it is must to have the accurate information on the prevalence of the circulating bacteria. Before the present study the information regarding the prevalence of the Salmonella spp. in the river Yamuna in Delhi region appeared insufficient, so the study was uptaken to study the prevalence of MDR Salmonella spp. in the water of river Yamuna that reaches to a larger section of human and animal population in Delhi region. Further to mention that the patients infected with MDR Salmonella are at higher risks of developing bacteraemia and deaths than those who are infected with the susceptible strains (Varma et al., 2005). In the present study the Yamuna being a major tributary of river Ganges revealed the presence of MDR Salmonella in similar way as it was found in a study conducted in different locations of river Ganges and 24 MDR isolates of Salmonella were obtained (Kalaiyarasu, Saxena, \& Gupta, 2013). All the isolates obtained from Ganges were 100\% resistant to Ampicillin like in our study and also showed lower resistance to the Ciprofloxacin similar to our results where isolates obtained from Yamuna were less resistant to Ciprofloxacin. These studies indicate the prevalence of MDR Salmonella spp. in the major rivers of Northern India. The water of the river Yamuna is polluted by various sources that leads to the selective pressure and increase in AMR in circulating bacteria. The water harbours a wide variety of Salmonella spp. that is both pathogenic and non-pathogenic in nature and could have been originated from human, animal or environmental source. The isolates obtained from the river Yamuna were multidrug resistant with varied resistance. Though samples were collected randomly in three seasons comprising winters, summers and rains with minimum of 5 samples from each location at different time intervals and different spots but Yamuna bank samples were found positive for Salmonella spp. in all seasons of sample collection, the samples were positive for Salmonella spp. even during flood when water from Hathini Barrage of Haryana was released flooding the river. Hence it showed the constant prevalence of Salmonella spp. in Yamuna Bank area of Yamuna river of Delhi region. Though water of Okhla barrage was much polluted raising expectation of finding Salmonella spp. and other pathogenic bacteria but no specific genera were identified except unidentified coliforms. Out of Salmonella spp. isolated from Yamuna water maximum were isolated from Yamuna Bank area with exception of one that was obtained from ITO Bridge. No Salmonella spp. could be isolated from the water samples collected from other location including all the locations of Haryana and 
Uttar Pradesh. Though the major serovars isolated from the river Yamuna were $S$. Typhimurium but on serotyping one belonged to Group C2 that is a non typhoidal Salmonella (NTS) which can cause septicaemia and focal infections like meningitis, endocarditis or osteomyelitis. This isolate of Group C2 may be Salmonella Bovismorbificans (Manning, Gole, \& Chousalkar, 2015), Salmonella Newport (Frye \& Fedorka-Cray, 2007) or any other serovar of group C. In human non-typhoidal serovars cause 93 million enteric infections and 155,000 diarrhoeal deaths each year. (Majowicz et al., 2010) Salmonella Newport, (Kumar, Gupta, Vaish, \& Gupta, 2016) cause enteritis in Cattle and has also been reported as a major cause of non-typhoidal foodborne infections resulting in outbreaks due to consumption of contaminated food items (Foley \& Lynne, 2008). In this study Salmonella Typhimurium was found as a major pathogen in water of river Yamuna. $S$. Typhimurium is found in both human and animals though it can cause diseases in a large range of host species, (Tsolis et al., 1999) as it exhibit significant variation in its host preference. Salmonella Typhimurium is invasive in nature but not host adapted and may cause dreadful systemic infections in a wide range of host especially more invasive infection in immunocompromised host. (P.A. \& T.J., 1993) In present study Ampicillin, Cefotaxime, Clindamycin and Nitrofurantoin were found to be $100 \%$ resistant where as Aztreonam, Chloramphenicol, Chloramphenicol, COT, Levofloxacin Tetracycline in showed no resistance (Table 2). Salmonella is reported in many Indian studies as invariably sensitive to Chloramphenicol, (Shekhar \& Singh, 2014) like the result obtained in present study. Streptomycin exhibited higher resistance $81.81 \%$ resistance and the combination of Amoxicillin and Clavulanic acid as $63.63 \%$. Gentamicin as $45.45 \%$, Nalidixic acid as
$36.36 \%$ whereas Azithromycin and Ceftazidime both had $27.27 \%$ resistance and Ceftriaxone, Ciprofloxacin and Piperacillin and Tazobactum showed less resistance as $9.09 \%$. In our study the isolate S2 of Group C2 showed resistance to five antibiotics comprising Cefotaxime, Nitrofurantoin, Streptomycin, Piperacillin and Tazobactum and was susceptible to rest of the antibiotics. The other isolate S14 was untypable considering it may be a new or uncommon or rare serovar. Though the phenomenon of emergence of new serovar is there in Salmonella spp. but the untypable/new serovar is needed to be studied in details regarding its virulence factor and potential to study its potential in contributing in emergence and spread of AMR. Though in our study this untypable serovar was found to be resistant for six antibiotics only out of 23 antibiotics tested and was susceptible for the rest of the antibiotics so its MARI (Table 4) is also not very high considering it not to have been originated from high risk of contamination. The other isolate S12 and S15 obtained from Yamuna water showed resistant for eight and ten antibiotics respectively which comprised Nalidixic acid but they showed susceptibility for Ciprofloxacin and Levofloxacin, still fluroquinolones may not completely eradicate the infection caused by the isolate as it was resistant to NA. Most of the isolates were intermediate sensitive for Nalidixic acid (S. et al., 2016) with few isolates as sensitive and rest as resistant with $36.36 \%$ resistance but Ciprofloxacin exhibited higher sensitivity like that of Levofloxacin thus revealing that second and fourth generation fluoroquinolones are still effective and resistance is not higher for them in Salmonella isolates obtained from river Yamuna whereas three Ciprofloxacin resistant strains were reported to have been isolated form river Ganga in North India (Kalaiyarasu et al., 2013). The isolates of Salmonella spp. 
tested with the combination of Amoxicillin and clavulanic acid, (Wong, Epstein, \& Westropp, 2015) showed resistance with exception for three isolates showing intermediate sensitivity. The overall resistant percentage observed was $63.63 \%$. Ampicillin was $100 \%$ resistant. Azithromycin, (Day et al., 2017) showed more sensitivity than resistant that was recorded as $27.27 \%$ only. The isolates were all resistant for Cefotaxime with $100 \%$ resistance. (T., 2015) Isolates were either resistant of Ceftazidime with $27.27 \%$ resistance or showed intermediate sensitivity $(63.63 \%)$ only one isolate exhibited sensitivity for Ceftazidime, whereas when ceftazidime was used in combination with clavulanic acid there was absolute sensitivity in all the isolates with no or zero percent resistance that showed that clavulanic acid inhibited the bacterial enzymes and allowed the ceftazidime to produce its effect. Ceftriaxone mainly produced intermediate sensitivity or few sensitive results with only one isolate as resistant and recorded $9.09 \%$ resistance. Chloramphenicol, (Ghatak et al., 2013) was all sensitive with zero resistance. Clindamycin was as usual resistant as it is reported to have no effect on gram negative bacteria and it showed presence of no mutant that gave any sensitive reaction for Clindamycin. Colistin, (Poirel, Jayol, \& Nordmanna, 2017) produced larger ZI in reference to the ZI described for ATCC 25922 as it is not defined for Enterobacteriaceae so Colistin was considered sensitive. Cotrimoxazole, (Nhung, Chansiripornchai, \& Carrique-Mas, 2017) produced absolute sensitive results with zero percent resistance in all the isolates. Gentamicin, (Poonia, Singh, \& Tsering, 2014) was sensitive as well as resistant in many isolate the overall resistance recorded was $45.45 \%$. Meropenem was sensitive or intermediate sensitive with no resistance. But all the isolates were $100 \%$ resistant for Nitrofurantoin. The isolates were mostly intermediate sensitive for combination of Piperacilin and Tazobactum (Quan et al., 2017) with $9.09 \%$ resistance only. Polmyxin $\mathrm{B}$ produced larger ZI like in case of Colistin (Giamarellou \& Poulakou, 2009). The streptomycin was all resistant with $81.81 \%$ resistance and exception of few being intermediate sensitive (Davis, 1987). Tetracycline was sensitive or intermediate sensitive with no resistant isolate (Winokur et al., 2000). Tigecycline, (Quan et al., 2017) also produced the similar results as Tetracycline with higher sensitivity. The MARI obtained from all the MDR isolates was found to be varying from 0.208 to 0.417 with average MARI as 0.297. The MARI above 0.2 is considered to have originated from source of high risk of contamination. The MARI in present study is very high compare to other studies reporting maximum MARI as 0.67 in Salmonella Typhimurium (Shekhar \& Singh, 2014). The isolates were tested against 26 FDA approved drugs and on examining the drug resistance pattern it was noticed that all the isolates were MDR and were resistant to maximum of 10 drugs and minimum of 5 drugs (Table 3 ).

In conclusion the study revealed the presence of multidrug resistant Salmonella spp. in water of the river Yamuna in Delhi region though the prevalence was not high and most of the isolates were obtained from Yamuna Bank region in Delhi. Salmonella Typhimurium was the major serovar detected in serotyping that causes invasive and systemic infection in wide range of hosts. Salmonella isolates exhibited high level of resistance and MARI that raise the public health concern of dissemination of AMR genes to the other pathogenic and nonpathogenic bacteria in the river water via horizontal gene transmission thereby contributing in the increase of the AMR, so effective measure and guidelines needs to be formulated to contain the spread of AMR in Salmonella spp. in the water of river Yamuna 
to further protect the vulnerable population of human and animals that coming in contact with river water.

\section{Acknowledgement}

We thank the Centre for drug design, discovery and development (C4D) of SRM University, Haryana for providing the necessary research facilities and the Government of India, CCS National Institute of Animal Health, Baghpat (U.P.) for their support for this study. The finding and conclusions in this report are those of authors and do not represent the official position of any of the above organization.

Conflict of Interest: None declared

Ethical approval: This article does not contain any studies with human participants or animals performed by any of the authors.

\section{References}

Achtman, M., Wain, J., Weill, F. X., Nair, S., Zhou, Z., Sangal, V., ... Brisse, S. (2012). Multilocus sequence typing as a replacement for serotyping in Salmonella enterica. PLoS Pathogens. https://doi.org/10.1371/journal.ppat.100 2776

Ahammad, Z. S., Sreekrishnan, T. R., Hands, C. L., Knapp, C. W., \& Graham, D. W. (2014). Increased waterborne bla NDM1 resistance gene abundances associated with seasonal human pilgrimages to the Upper Ganges River. Environmental Science and Technology. https://doi.org/10.1021/es405348h

Angulo, F. J., Tippen, S., Sharp, D. J., Payne, B., Collier, C., Hill, J. E., Swerdlow, D. L. (1997). A community waterborne outbreak of salmonellosis and the effectiveness of a boil water order. American Journal of Public Health.
https://doi.org/10.2105/AJPH.87.4.580

Arthur L. Barry, William A. Craig, Harriette Nadler,:. Barth reller, Christie C. Sanders, J. M. S. (2016). M26-A: Methods for Determining Bactericidal Activity of Antimicrobial Agents; Approved Guideline. International Clinical Laboratory Standard Guidelines ICLS.

Azam, M., Jan, A. T., \& Haq, Q. M. R. (2016). blaCTX-M-152, a Novel Variant of CTX-M-group-25, Identified in a Study Performed on the Prevalence of Multidrug Resistance among Natural Inhabitants of River Yamuna, India. Frontiers in Microbiology. https://doi.org/10.3389/fmicb.2016.001 76

Blood, R. M., \& Curtis, G. D. W. (1995). Media for 'total' Enterobacteriaceae, coliforms and Escherichia coli. Progress in Industrial Microbiology. https://doi.org/10.1016/S00796352(05)80012-8

Chiu, C. H., \& Ou, J. T. (1996). Rapid identification of Salmonella serovars in feces by specific detection of virulence genes, invA and spvC, by an enrichment broth culture- multiplex PCR combination assay. Journal of Clinical Microbiology. https://doi.org/10.1128/jcm.34.10.26192622.1996

CLSI. (2016). Performance Standards for Antimicrobial Susceptibility Testing CLSI supplement M100S. In Clinical and Laboratory Standards Institute, Wayne, PA.

Coates, A., \& Hu, Y. (2018). Antibiotics and AMR: A global perspective. Drug Discovery World.

Davis, B. D. (1987). Mechanism of bactericidal action of aminoglycosides. Microbiological Reviews. https://doi.org/10.1128/mmbr.51.3.341350.1987 
Day, M., Doumith, M., Jenkins, C., Dallman, T. J., Hopkins, K. L., Elson, R., Woodford, N. (2017). Antimicrobial resistance in Shiga toxin-producing Escherichia coli serogroups $\mathrm{O} 157$ and O26 isolated from human cases of diarrhoeal disease in England, 2015. Journal of Antimicrobial Chemotherapy. https://doi.org/10.1093/jac/dkw371

Dechet, A. M., Scallan, E., Gensheimer, K., Hoekstra, R., Gunderman-King, J., Lockett, J., ... Sobel, J. (2006). Outbreak of multidrug-resistant Salmonella enterica serotype typhimurium definitive type 104 infection linked to commercial ground beef, Northeastern United States, 20032004. Clinical Infectious Diseases. https://doi.org/10.1086/500320

European Committee on Antimicrobial Susceptibility Testing. (2016). Breakpoint tables for interpretation of MICs and zone diameters Version 6.0, valid from 2016-01-01. In http://www.eucast.org/fileadmin/src/me dia/PDFs/EUCAST_files/Breakpoint_ta bles/v_5.0_Breakpoint_Table_01.pdf.

Ewing, W. H. (1986). Edwards and Ewing's identification of Enterobacteriaceae. Edition 4.

Foley, S. L., \& Lynne, A. M. (2008). Food animal-associated Salmonella challenges: pathogenicity and antimicrobial resistance. Journal of Animal Science. https://doi.org/10.2527/jas.2007-0447

Frye, J. G., \& Fedorka-Cray, P. J. (2007). Prevalence, distribution and characterisation of ceftiofur resistance in Salmonella enterica isolated from animals in the USA from 1999 to 2003. International Journal of Antimicrobial Agents.

https://doi.org/10.1016/j.ijantimicag.200 7.03.013 fssai. (2016). Mannual of Methods of Analysis of Food-Water.

Ghatak, S., Singha, A., Sen, A., Guha, C., Ahuja, A., Bhattacharjee, U., ... Jana, P. S. (2013). Detection of new delhi metallo-beta-lactamase and extendedspectrum beta-lactamase genes in escherichia coli isolated from mastitic milk samples. Transboundary and Emerging Diseases. https://doi.org/10.1111/tbed.12119

Giamarellou, H., \& Poulakou, G. (2009). Giamarellou H, Poulakou G. Multidrugresistant Gram-negative infections: what are the treatment options? Drugs. 2009;69(14):1879-901. In Drugs. https://doi.org/10.2165/11315690000000000-00000

González-Zorn, B., \& Escudero, J. A. (2012). Ecology of antimicrobial resistance: Humans, animals, food and environment. International Microbiology. https://doi.org/10.2436/20.1501.01.163

Huehn, S., La Ragione, R. M., Anjum, M., Saunders, M., Woodward, M. J., Bunge, C., ... Malorny, B. (2010). Virulotyping and antimicrobial resistance typing of Salmonella enterica serovars relevant to human health in Europe. Foodborne Pathogens and Disease. https://doi.org/10.1089/fpd.2009.0447

Kalaiyarasu, S., Saxena, M. K., \& Gupta, R. S. (2013). Emerging of multiple drug resistance in Salmonella typhimurium serovars isolated from Indian Ganga river. Advances in Animal and Veterinary Sciences.

Kumar, Y., Gupta, N., Vaish, V. B., \& Gupta, S. (2016). Distribution trends \& antibiogram pattern of Salmonella enterica serovar Newport in India. Indian Journal of Medical Research. https://doi.org/10.4103/09715916.193293

Lavigne, J. P., \& Blanc-Potard, A. B. (2008). 
Molecular evolution of Salmonella enterica serovar Typhimurium and pathogenic Escherichia coli: From pathogenesis to therapeutics. Infection, Genetics and Evolution. https://doi.org/10.1016/j.meegid.2007.1 1.005

Mackie and McCartney Practical Medical Microbiology, 14th edition. (1996). Journal of Medical Microbiology. https://doi.org/10.1099/00222615-45-6$512 \mathrm{~b}$

Majowicz, S. E., Musto, J., Scallan, E., Angulo, F. J., Kirk, M., O’Brien, S. J., Hoekstra, R. M. (2010). The Global Burden of Nontyphoidal Salmonella Gastroenteritis. Clinical Infectious Diseases.

https://doi.org/10.1086/650733

Malorny, B., Hoorfar, J., Bunge, C., \& Helmuth, R. (2003). Multicenter validation of the analytical accuracy of Salmonella PCR: Towards an international standard. Applied and Environmental Microbiology. https://doi.org/10.1128/AEM.69.1.290296.2003

Malorny, B., Huehn, S., Dieckmann, R., Krämer, N., \& Helmuth, R. (2009). Polymerase chain reaction for the rapid detection and serovar identification of Salmonella in food and feeding stuff. Food Analytical Methods. https://doi.org/10.1007/s12161-0089057-9

Maness, P. C., Smolinski, S., Blake, D. M., Huang, Z., Wolfrum, E. J., \& Jacoby, W. A. (1999). Bactericidal activity of photocatalytic $\mathrm{TiO} 2$ reaction: Toward an understanding of its killing mechanism. Applied and Environmental Microbiology. https://doi.org/10.1128/aem.65.9.40944098.1999

Manning, J., Gole, V., \& Chousalkar, K. (2015). Screening for Salmonella in backyard chickens. Preventive Veterinary Medicine. https://doi.org/10.1016/j.prevetmed.201 5.03.019

Mooijman, K. A. (2018). The new ISO 65791: A real horizontal standard for detection of Salmonella, at last! Food Microbiology. https://doi.org/10.1016/j.fm.2017.03.00 1

Nhung, N. T., Chansiripornchai, N., \& Carrique-Mas, J. J. (2017). Antimicrobial resistance in bacterial poultry pathogens: A review. Frontiers in Veterinary Science. https://doi.org/10.3389/fvets.2017.0012 6

P.A., G., \& T.J., D. (1993). The Salmonella typhimurium virulence plasmid increases the growth rate of Salmonellae in mice. Infection and Immunity.

Perilla, M., Ajello, G., Bopp, C., Elliott, J., Facklam, R., Knapp, J., ... CDC. (2003). Manual for the laboratory identification and antimicrobial susceptibility testing of bacterial pathogens of public health importance in the developing world. World Health Organization (WHO).

Poirel, L., Jayol, A., \& Nordmanna, P. (2017). Polymyxins: Antibacterial activity, susceptibility testing, and resistance mechanisms encoded by plasmids or chromosomes. Clinical Microbiology Reviews. https://doi.org/10.1128/CMR.00064-16

Poonia, S., Singh, T. S., \& Tsering, D. C. (2014). Antibiotic susceptibility profile of bacteria isolated from natural sources of water from rural areas of East Sikkim. Indian Journal of Community Medicine. https://doi.org/10.4103/09700218.137152

Quan, J., Li, X., Chen, Y., Jiang, Y., Zhou, Z., Zhang, H., ... Yu, Y. (2017). 
Prevalence of mcr-1 in Escherichia coli and Klebsiella pneumoniae recovered from bloodstream infections in China: a multicentre longitudinal study. The Lancet Infectious Diseases. https://doi.org/10.1016/S14733099(16)30528-X

Rahn, K., De Grandis, S. A., Clarke, R. C., McEwen, S. A., Galán, J. E., Ginocchio, C., Gyles, C. L. (1992). Amplification of an invA gene sequence of Salmonella typhimurium by polymerase chain reaction as a specific method of detection of Salmonella. Molecular and Cellular Probes. https://doi.org/10.1016/08908508(92)90002-F

S., G., N., M., E.Y., K., A., A., V., N., M., K., ... R., L. (2016). Trends in antibiotic resistance among major bacterial pathogens isolated from blood cultures tested at a large private laboratory network in India, 2008-2014. International Journal of Infectious Diseases. https://doi.org/10.1016/j.ijid.2016.08.00 2

Shekhar, C., \& Singh, S. P. (2014). Antimicrobial resistance and molecular characterization of Salmonella serovars from man and animals. Indian Journal of Animal Sciences.

T., B. (2015). Antimicrobial interactions: Mechanisms and implications for drug discovery and resistance evolution. Current Opinion in Microbiology.

Todar, K. (2016). Todar's Online Textbook of Bacteriology.

Tsolis, R. M., Townsend, S. M., Miao, E. A., Miller, S. I., Ficht, T. A., Adams, L. G., \& Bäumler, A. J. (1999). Identification of a putative Salmonella enterica serotype typhimurium host range factor with homology to IpaH and YopM by signature-tagged mutagenesis. Infection and

Immunity. https://doi.org/10.1128/iai.67.12.6385-

6393.1999

Varma, J. K., Mølbak, K., Barrett, T. J., Beebe, J. L., Jones, T. F., Rabatsky-Ehr, T., Angulo, F. J. (2005). Antimicrobialresistant nontyphoidal Salmonella is associated with excess bloodstream infections and hospitalizations. Journal of Infectious Diseases. https://doi.org/10.1086/427263

Vo, A. T. T., Van Duijkeren, E., Gaastra, W., \& Fluit, A. C. (2010). Antimicrobial resistance, class 1 integrons, and genomic island 1 in Salmonella isolates from Vietnam. PLoS ONE. https://doi.org/10.1371/journal.pone.000 9440

Wales, A., \& Davies, R. H. (2013). Environmental aspects of Salmonella. In Salmonella in domestic animals. https://doi.org/10.1079/9781845939021. 0399

Walsh, C., (2003). No TitleAntibiotics: actions, origins, resistance. American Society for Microbiology (ASM).

WHO. (2001). 2001 Executive summary WHO Global Strategy for Containment of Antimicrobial Resistance. World Health.

Winokur, P. L., Brueggemann, A., DeSalvo, D. L., Hoffmann, L., Apley, M. D., Uhlenhopp, E. K., ... Doern, G. V. (2000). Animal and human multidrugresistant, cephalosporin-resistant Salmonella isolates expressing a plasmid-mediated CMY-2 AmpC $\beta$ lactamase. Antimicrobial Agents and Chemotherapy.

https://doi.org/10.1128/AAC.44.10.277 7-2783.2000

Wong, C., Epstein, S. E., \& Westropp, J. L. (2015). Antimicrobial susceptibility patterns in urinary tract infections in dogs (2010-2013). Journal of Veterinary Internal Medicine. https://doi.org/10.1111/jvim.13571 


\section{How to cite this article:}

Shingini Sharma, V. Samuel Raj, Kusum Rani and Rashmi Tyagi. 2021. Isolation of Multidrug Resistant Salmonella spp. from the River Yamuna in Delhi Region of India. Int.J.Curr.Microbiol.App.Sci. 10(02): 172-187. doi: https://doi.org/10.20546/ijcmas.2021.1002.022 